\title{
COMMENTARY
}

\section{Training Toward Our Future: Questions About Length of Training in Family Medicine Programs}

Suki Tepperberg, MD, MPH; Katherine Gergen Barnett, MD; Joshua Fischer, MD, PhD; Mark Johnson, MD; Sarah Coles, MD; Thomas Hines, MD

(Fam Med. 2019;51(8):636-7.)

doi: 10.22454/FamMed.2019.711802

E nsuring a robust, high-quality primary care workforce is an urgent priority. As alternative training options for physician assistants and nurse practitioners are expanding, there is an interest in examining the appropriate length of training for family medicine residents. While some argue that it takes more than 3 years to train a family physician in the traditional comprehensive scope of work, others contend that extending residency duration to 4 years would reduce the number and quality of applicants attracted to the field. The Length of Training Pilot (LOTP), an extensive case-control study with robust participation, is underway to explore the impact of longer training for family physicians with a focus on scope of practice, clinical skills, and trainee satisfaction. ${ }^{1}$ While the initial results from Eiff, et $\mathrm{al}^{1}$ on applicant characteristics and match results do not demonstrate significant differences in recruitment between 3-year and 4-year programs, it is clear that the true impact of extending family medicine residency remains undetermined, especially regarding the recruitment of women, underrepresented minority (URM) candidates, and applicants with substantial medical debt.

As residency leadership from some of the participating 3-year programs in this study, we are specifically eager to know if gender and debt burden influence an applicant's decision to pursue a longer training program. We know that there are significantly more women graduating from family medicine residencies than men. ${ }^{2}$ It was previously reported that women are more likely to express interest in 4 years of training than men. ${ }^{2}$ Yet in this study there was a significantly larger percentage of women in the 3-year control group relative to the 4-year programs. We would like to see the study results analyzed by gender. Additionally, student debt is a potential contributing factor in the decision of which specialty to pursue. Data presented previously show an inverse relationship between a resident's educational debt and their interest in additional residency training. ${ }^{2-4}$ We encourage further study to determine whether it will be more difficult to recruit debt-burdened students to a 4-year family medicine training program. Since URM candidates may be more likely to carry the highest debt burden, it is also important to analyze debt-related results by URM status. ${ }^{5}$

As participants in the LOTP study, we are also concerned about the effect of extending residency duration on typical training programs. The design of the study and selection criteria likely resulted in more competitive and better-resourced residency programs being

From the Boston University Department of Family Medicine (Drs Tepperberg, Barnett, and Hines); North Colorado Family Medicine, Greeley, CO (Dr Fischer); University of Arizona College of Medicine-Phoenix Department of Family, Community, and Preventive Medicine (Dr Coles); and Swedish Family Medicine-Ballard, Seattle, WA (Dr Johnson). 
included in both the 3-year and 4-year cohorts. A program's decision to apply for participation in the LOTP 4-year track implies that they had the resources and underlying strength to successfully engage in a substantial modification to their program. The number of applicants from US medical schools to both 3-year and 4-year LOTP programs was higher than the national average and the mean number of international medical graduate applicants was consistently lower. Selecting for more competitive programs for the LOTP might have diminished the impact of program duration on the match results, since stronger programs inherently attract more candidates. We would like to explore whether typical programs would thrive in a move to a 4-year structure.

We were also interested to see how applicant interest in 4-year programs changed in the years from 2015-2018. Prior to 2015, most 4-year programs did not have fourth-year residents in their programs. In fact, 2015 was the first year that most program applicants could talk with fourth-year residents currently working in a 4-year program, and the first time a resident in their fourth year could address applicant questions and concerns. Given that applicants often use information from current residents to inform their opinions about a program, how are residents in their fourth year influencing applicants who are considering both 4- and 3-year programs? Knowing that only $25 \%-33 \%$ think a fourth year is necessary, it is reasonable to further explore fourth-year resident advice to applicants.

There are significant issues with using the "mean number of ranks to fill per position offered in the match/program" as a comparator between programs. While this metric may be useful internally for a program when developing its recruitment process and examining questions such as those raised above, it is unclear if it can be used to compare one program or one cohort to another. Given the dramatic increase in applicants per spot during the same years as this study, there are many variables not captured in this metric. Highperforming programs may have higher-quality applicants throughout the entire rank list but match further down the list than programs attracting lower-quality applicants. Indeed, different programs may have different priorities in ranking candidates, such as the importance of academics, urban vs rural health, or recruitment of a more diverse resident class. Geography can also play a role. Programs in locations deemed to be desirable may get a larger volume of applicants interested in taking a look, but not necessarily ready to make a commitment. Others in what some might consider less desirable locations might get fewer applicants, but attract a higher percentage of individuals who, due to personal, family, or other reasons might be much more likely to rank the program highly.

This initial report on the match results for the LOTP provides a thought provoking and well analyzed assessment of this first phase of outcomes. We know that increasing primary care improves health outcomes and reduces $\operatorname{costs}^{6}$ and that an expanded commitment to a diverse workforce is key to addressing health disparities. ${ }^{7}$ For these reasons it is essential that family medicine educators further evaluate the LOTP results to identify the system that will meet future primary care demands. The LOTP is an admirable start, and we look forward to future publications arising from this study that consider the implications of a longer residency for programs, graduates, and society.

CORRESPONDING AUTHOR: Address correspondence to Dr Suki Tepperberg, One Boston Medical Center Place, Department of Family Medicine, Dowling 5 South, Boston, MA 02118. Fax: 617-414-3345. suki.tepperberg@bmc.org.

\section{References}

1. Eiff MP, Ericson A, Uchison EW, et al. A comparison of residency applications and match performance to 3-year versus 4-year family medicine training programs. Fam Med. 2019;51(8):641-648.

2. Carney PA, Eiff MP, Waller E, Peterson LE. Factors Associated With Interest in Pursuing a Fourth Year of Family Medicine Residency Training. Fam Med. 2017;49(5):339-345.

3. Phillips JP, Petterson SM, Bazemore AW, Phillips RL. A retrospective analysis of the relationship between medical student debt and primary care practice in the United States. Ann Fam Med. 2014;12(6):542-549.

4. Grischkan J, George BP, Chaiyachati K, Friedman AB, Dorsey ER, Asch DA. Distribution of Medical Education Debt by Specialty, 2010-2016. JAMA Intern Med. 2017;177(10):15321535.

5. Association of American Medical Colleges. Diversity in Medical Education Facts \& Figures 2016: United States. http:// www.aamcdiversityfactsandfigures2016.org. Accessed December 8, 2018 .

6. Obucina M, Harris N, Fitzgerald JA, et al. The application of triple aim framework in the context of primary healthcare: A systematic literature review. Health Policy. 2018;122(8):900907.

7. Marrast LM, Zallman L, Woolhandler S, Bor DH, McCormick D. Minority physicians' role in the care of underserved patients: diversifying the physician workforce may be key in addressing health disparities. JAMA Intern Med. 2014;174(2):289-291. 